ORIGINAL ARTICLE

\title{
Prostate Specific Antigen (PSA): Normal Reference Value in Bangladeshi Male, a Retrospective PSA Analysis of 765 Male
}

\author{
*MT Rahman ${ }^{1}$, TT Sajani ${ }^{2}$, R Sultana ${ }^{3}$, S R Choudhury ${ }^{4}$, MMR Siddiqui $^{5}$ \\ ${ }^{1}$ Prof. Dr. Md. Tahminur Rahman, Professor and Head, Pathology, Anwer Khan Modern Medical College, Dhaka \\ ${ }^{2}$ Dr. Tabassum Tahmin Sajani, Assistant Professor, Community Medicine \\ Anwer Khan Modern Medical College, Dhaka \\ ${ }^{3}$ Dr. Rosy Sultana, Assistant Professor, Immunology, BIRDEM, Dhaka \\ ${ }^{4}$ Dr. Sohel Reza Choudhury, Professor, Epidemiology and Research, National Heart Foundation \\ Hospital and Research Institute, Dhaka \\ ${ }^{5}$ Dr. Md. Mahmudur Rahman Siddiqui, Assistant Professor, Medicine, Anwer Khan Modern Medical College, Dhaka \\ *Corresponding author
}

ABSTRACT

Prostate specific antigen (PSA) is an important tool for the diagnosis, prognosis and follow up of prostatic cancer, the most common malignancy of the male throughout the world. It is safe, reliable, specific, noninvasive test if done properly. However there are many benign, inflammatory and other prostatic conditions which can also give rise to elevated PSA value and thus limits its use. Different methods of estimation may also give rise to variable PSA level. More over the normal reference range may be variable depending on the age, geographic situation, environmental conditions and other factors. The normal reference range mentioned in the texts is based on findings in the developed countries. No effort was made before to see the normal reference PSA value among Bangladeshi male population. With this background the present study was undertaken to determine the normal reference value of PSA in Bangladeshi population. It is evident form the present study that the normal reference PSA value for Bangladeshi male in different age groups are lower in comparison to that of upper limit of normal reference value mentioned in the text.

Key word: Prostate specific antigen PSA, normal reference value, Bangladeshi male

\section{Introduction}

Prostate specific antigen (PSA) is an important tool to detect prostate cancer, the most common malignancy of the male throughout the world, yet increased PSA alone does not reflect the presence of prostate cancer. Prostate specific antigen (PSA) is a glycoprotein (molecular weight 33-34,000 dalton containing 7\% carbohydrate by weight) which is kallikrein like serine protease secreted by secretory cells located in the luminal side of the prostatic gland ${ }^{1}$. PSA is immunologically specific for prostatic tissue; it is present in normal, benign, hyperplasic and malignant prostatic tissue, in metastatic prostatic carcinoma and also in prostatic fluid and seminal plasma. PSA is not found in any other normal tissue obtained from men or other cancers and also not found in apparently healthy woman or women with cancer. Besides it is functionally and immunologically distinctive form prostatic Acid Phosphates (PAP) $2,3,4,5,6,7$. PSA test is one of the best ways to screen for prostatic cancer. Many studies in the developed countries consider the normal PSA reference value 0$4 \mathrm{ng} / \mathrm{ml}$ and $>20 \mathrm{ng} / \mathrm{ml}$ is considered highly elevated. However any abnormal PSA value does not necessarily mean cancer. Other pathological prostatic conditions such as prostatitis and benign prostatic hyperplasia (BPH) may also increase the level of PSA. In such abnormal cases, repeat and serial PSA dilution is advised and a digital per rectal examination, per rectal ultrasonography or MRI is advised. 
Recommended age specific upper reference range of serum PSA accepted internationally are:

$\begin{array}{lc}\text { Age range } & \text { PSA level } \\ 40-49 \text { years } & 2.5 \mathrm{ng} / \mathrm{ml} \\ 50-59 \text { years } & 3.5 \mathrm{ng} / \mathrm{ml} \\ 60-69 \text { years } & 4.5 \mathrm{ng} / \mathrm{ml} \\ 70-79 \text { years } & 6.5 \mathrm{ng} / \mathrm{ml}\end{array}$

PSA is organ specific but not cancer specific. Serum PSA level is less perfect for detection of early prostate cancer but there is little doubt that serial measurements of PSA are of great value in assessing response to therapy. Any rise after surgery indicates recurrence, disseminated disease or residual cancer ${ }^{8}$. The preoperative PSA value is a significant independent clinical factor for relapse after radical prostatectomy and also predictive for larger, more aggressive and more locally advanced tumors 9,10 . In one study out of 190 men with elevated PSA 143 (3.6\%) under went trans rectal ultrasonography guided biopsy of the prostate and 42 men (1\% of total $29.3 \%$ of men undergoing biopsy) were found to have cancer ${ }^{11}$.

The rate of rise of PSA in a man having cancer and man without cancer is $0.75 \mathrm{ng} / \mathrm{ml}$ per year. For valid test it requires that there be at least ${ }^{3}$ PSA measurements per year over a period of 1.5-2 years. This is because there is substantial short term variability (20\%) between PSA measurements. PSA exists in two forms free PSA (minor fraction) and total PSA (major fraction bound to antichymotrypsin and minor fraction bound to alpha 2macroblobulin. Any remaining PSA is in the free form. The percentage of free PSA (free PSA/total PSAX100) is lower in men with prostate cancer and higher in benign prostatic lesion. It is more so when the total PSA level is in grey zone ie 4$10 \mathrm{ng} / \mathrm{ml}$. When free PSA $\%$ is above $25 \%$, it indicates low risk or cancer free PSA\% lower than $10 \%$ are worrisome for cancer. In one study in USA, PSA value over ${ }^{4} .1 \mathrm{ng} / \mathrm{ml}$ showed sensitivity of $93.8 \%$ and slightly better performances in men younger than 70 years ${ }^{12}$. Another study in Brazil showed better chances for curing low grade prostate cancer occur in individuals with normal PSA for whom a biopsy is not usually recommended ${ }^{13}$.

Mild elevation of PSA in serum is seen in nodular hyperplasia, prostatic, Prostatitis infarct, major trauma to the prostate such as needle biopsy, TURP14. But the elevation is transient and resolve with proper treatment. PSA level also rises after recent sexual activity or a cystoscopy. Larger doses of some medications used to treat cancer such as cyclophosphamide, diethylstilbestrol, metho trexate can interfere with test results.

\section{Methods and subjects}

A total of 765 males blood samples referred to National Diagnostic network (NHN), Dhaka one of the largest consultancy and diagnostic center under Diabetic Association of Bangladesh between the period of January to June 2005 from different sub center and braches of NHN at Dhaka for some other biochemical tests other than PSA. All the samples were tested for total PSA estimation by ELISA method using commercially available kits form DRG International Inc, GmbH Germany. 94 samples were tested in each batch using low and high control QC. All the low and high values were subjected to repeat ELISA. All the data were entered in computer excel program. Age group specific mean and standard error of mean were calculated. However as the PSA values were not normally distributed and to calculate the reference range, age group specific percentile values were calculated. Subjects with PSA value of 0 and $>80$ were not included in the study.

\section{Ethical Issue}

As these blood samples were sent for some other biochemical test other than PSA and would be discarded after testing verbal permission for the Director and lab in charge were taken for estimation of PSA using kit purchased by the authors.

\section{Principle of the PSA (ELISA) test}

The PSA-Elisa test is based on the principle of a solid phase enzyme linked immunosorbent assay. The assay utilizes a rabbit anti PSA antibody directed against infect PSA for solid phase immobilization on the micro-titer well. A monoclonal anti PSA antibody conjugated to 
horse radish neroxidease (HRPO) is in the antibody enzyme conjugate solution. The test sample is first allowed to react with the immobilized rabbit antibody in room temperature for 60 minutes. The wells are then washed to remove any unbound antigens. The monoclonal anti PSA HRPO conjugate is then reacted with the immobilized antigen for 60 minutes at room temperature resulting in the PSA molecules being sandwiched between the solid phase and the enzyme linked antibodies. The wells are rewashed with water to remove unbound labeled antibodies. A solution of TMB reagent is added and incubated at room temperature for 20 minutes resulting in the development of a blue color. The color development is stopped with the addition of stop solution changing the color to yellow. The concentration of PSA is directly proportional to the color intensity of the test sample. Absorbance is measured spectrophotometrically using $490 \mathrm{~nm}$ filter ${ }^{15}$.

\section{Results and observation}

Distribution of patients in different age groups with PSA value in $\mathrm{ng} / \mathrm{ml}($ mean \pm SE) are shown in table ${ }^{1,2,3}$.

Table- I: Showing distribution of subjects

\begin{tabular}{ccc}
\hline Age groups & Frequency & Percent \\
\hline 40 - 49 years & 57 & 7.5 \\
50 - 59 years & 178 & 23.3 \\
$60-69$ years & 316 & 41.3 \\
$70-79$ years & 178 & 23.3 \\
$80-89$ years & 36 & 4.7 \\
\hline
\end{tabular}

Table-II: Difference between PSA value in Bangladeshi males in this study and existing accepted PSA value world wide

\begin{tabular}{lcc}
\hline Age groups & $\begin{array}{c}\text { PSA value of Bangladeshi male, } \\
\text { present study (mean } \pm \text { SE) }\end{array}$ & $\begin{array}{c}\text { Existing upper limit of PSA } \\
\text { value accepted internationally }\end{array}$ \\
\hline 40 - 49 years & $1.6 \pm 0.2$ & $2.5 \mathrm{ng} / \mathrm{ml}$ \\
50 - 59 years & $2.9 \pm 0.4$ & $3.5 \mathrm{ng} / \mathrm{ml}$ \\
60 - 69 years & $3.0 \pm 0.2$ & $4.5 \mathrm{ng} / \mathrm{ml}$ \\
70 - 79 years & $4.8 \pm 0.6$ & $6.5 \mathrm{ng} / \mathrm{ml}$ \\
80 - 89 years & $5.2 \pm 2.2$ & \\
\hline
\end{tabular}

Table-III: Age group specific percentile distribution of PSA

\begin{tabular}{lccccccc}
\hline Age group & $\mathbf{5}$ & $\mathbf{1 0}$ & $\mathbf{5}$ & $\mathbf{5 0}$ & $\mathbf{7 5}$ & $\mathbf{9 0}$ & $\mathbf{9 5}$ \\
\hline 40-49 years & 1.0 & 1.0 & 1.0 & 1.2 & 1.5 & 2.2 & 5.3 \\
50-59 years & 1.0 & 1.0 & 1.2 & 1.6 & 2.5 & 4.5 & 7.0 \\
60-69 years & 1.0 & 1.0 & 1.2 & 1.8 & 3.1 & 6.0 & 9.1 \\
70-79 years & 1.0 & 1.0 & 1.2 & 2.0 & 3.9 & 12.6 & 22.2 \\
80-89 years & 1.0 & 1.0 & 1.4 & 1.9 & 3.4 & 9.1 & 24.7 \\
\hline
\end{tabular}

\section{Discussion}

It is evident from this study that the normal range of PSA (mean \pm SE) in Bangladeshi population in different age groups for males aged 40-49 years, 50-59 years, 60-69 years, 7079 years, $80-89$ years are $1.6 \pm 0.2,2.9 \pm 0.4$, $3.0 \pm 0.2,4.8 \pm 0.6,5.2 \pm 2.2$ respectively. The values are a bit less in comparison to the existing internationally accepted reference PSA value mentioned above. So PSA value in Bangladeshi male should be interpreted cautiously and other testes like PRD examination, USG, PSAV and clinical examination should be done if a value is obtained around the existing upper limit reference value which is accepted internationally. But as this is a retrospective study and the sample size is not very large it may be used as a baseline study and the value can be used as a reference data in further studies involving PSA level in Bangladesh. However future studies with large number of samples are advocated to confirm these observations.

\section{Limitation}

As it is a retrospective study we could not identify the associated disease pattern of these cases and whether these patients were normal or suffering from prostatic inflammation, nodular hyperplasia, PIN or cancer. So whether this PSA value actually reflects the normal or disease prostate is difficult to ascertain. However these values may reflect the PSA value in different age groups of Bangladesh male and can be used as a baseline data for future research on PSA and prostatic lesion in Bangladesh. 


\section{Acknowledgement}

We are grateful to the BIHS authority for giving us verbal permission for this research and the male patients whose blood sample were tested for this study.

\section{References}

1. Salam MA. Principles and practice of Urology. Pub MAS publications, Bangladesh, 1st edition 2002, pp637-93.

2. Hara M, Kimura H. Two prostate specific antigens, gammasemino-protein beta microsemino-protein. J Lab Clin. 1992; 113: 541-48.

3. Yuan JJ, Coplen DE, Petros JA, et al. Effects of rectal examination, prostatic massage, ultrasonography and needle biopsy on serum prostate specific antigen levels. J Urol1992; 147: 810-14.

4. Wang MC, Papsidero LD, Kuriyama M, et al. Prostatic antigen; a new potential marker for prostatic cancer. Prostate. 1981; 2: 89-93.

5. Stowel LI, Sharman IE, Hamel K. An Enzyme linked Immunosorbent Assay (ELISA) for prostate specific antigen. Froensic sceience Intern. 1991; 50: 125-38.

6. Frankel AE, Rouse RV, Wang MC, et al. Monoclonal antibodies to a human prostate antigen. Canc Res.1982; 42: 3714.

7. Benson MC, Whang IS, Pantuck A, et al. Prostate specific antigen density; a means of distinguishing bening prostate hypertrophy and prostate cancer. J Urol. 1992; 147: 815-16.
8. Robbins Pathologic Basis of Diseases. Edt. Kumar, Abbas, Fausto, 7th edition. Pub Elsevier USA 2004, pp 1054-56.

10. Damico AV, Renshaw AA, Sussman B, et al. Pretreatment PSA velocity and risk of death from prostate cancer following external beam radiaton therapy. JAMA. 205Jul 27; 394(4): 493-4

9. Patel DA, Presti JC Jr, McNeal JE, et al. Preoperative PSA velocity is and independent prognostic factor for relapse after radical prostatectomy. J clin Oncol. 2005 Sept; 23(25): 6157-62.

11. Li XM, Zhang L, Li J, et al. Measurement of serum zinc improves prostate cancer detection efficiency in patients with PSA levels between $4 \mathrm{ng} / \mathrm{mL}$ and 10 ng/mL. Asian J Androl. 2005; 7:323-8.

12. Thompson IM, Ankerst DP, Chi C, et al. Operating characteristics of PSA in men with an initaila level of $3.0 \mathrm{ng} / \mathrm{ml}$ or lower. JAMA. $2005 \mathrm{Jul} \mathrm{6;} \mathrm{294(1):} \mathrm{66-}$ 70 .

13. Ackermans surgical Pathology, 9th edition, editor Juhan Rosai, Pub Elsevier USA, pp 1368-69.

14. Dall' oglio MF, Crippa A, Antunes AA, et al. Survival of patients with prostate cancer and normal PSA level treated by radical prostatectomy. Int Braz J Urol. 2005 May-Jun; 31 (3): 222-27.

15. Prostate Specific Antigen (PSA, EIA-1778), brochure supplied by DRG International Inc, USA. 